\title{
MILLER CYCLE ANALYSIS USING EGM
}

\author{
Bernardo Ribeiro \\ Departamento de Engenharia Mecânica \\ Universidade do Minho - Portugal \\ bernardor@dem.uminho.pt
}

\author{
Jorge Martins \\ Departamento de Engenharia Mecânica \\ Universidade do Minho - Portugal \\ jmartins@dem.uminho.pt
}

\begin{abstract}
The Entropy Generation Minimization (EGM) method is based on the analysis by three sciences (thermodynamics, fluid flow and heat transfer) of the different processes that may occur in a system or in an equipment. Herein the EGM method is applied to internal combustion engines to determine the entropy generation caused by different processes.

A model incorporating entropy generation calculations is used to assess various engines configurations. Otto cycle was tested and Variable Valve Timing (VVT) and Variable Compression Ratio (VCR) were applied so thermodynamic benefits could be tested and evaluated.

With the referred model, the Miller cycle variables are analyzed in order to establish the best working conditions of an engine under a certain load. The intake and exhaust valve timing, combustion start, compression ratio adjustment and heat transfer are the variables for which a best working condition is determined based on the minimization of the entropy generation of the several engine processes.
\end{abstract}

$\begin{array}{cl}\text { SYMBOLS } & \\ \mathrm{h} & \text { Specific Enthalpy } \\ \mathrm{I} & \text { Irreversibility } \\ \mathrm{m} & \text { Mass } \\ \mathrm{p} & \text { Pressure } \\ \mathrm{Q} & \text { Heat } \\ \mathrm{s} & \text { Specific Entropy } \\ \mathrm{S} & \text { Entropy } \\ \mathrm{S}_{\text {gen }} & \text { Entropy generated } \\ \mathrm{T} & \text { Temperature } \\ \mathrm{W} & \text { Work }\end{array}$

\section{INTRODUCTION}

Engine optimization has been made (theoretically) using several criteria. Whether by maximizing power or power density [1-4], maximizing the thermal efficiency, maximizing an ecological function $[5,6]$ or minimizing the entropy generated [10]. Internal combustion engines have also been analysed through exergy destruction [11-14].
The EGM method [7-10] is used to assess the amount of entropy generated during the working cycle of a certain thermal engine and proposing reduction measures for that entropy generated. The reduction of the entropy generated is similar to a more ecological working condition or more efficient working condition, once the energy source (the fuel, in internal combustion engines) is used mainly for useful energy production by the thermal engine.

This paper intends to go further than the studies presented up to date and has a more realistic approach to the problem of engine optimization. Indicated cycle conditions are used to calculate entropy generation, and improvement directions and limits are determined. The study herein presented represents an example of the use of the EGM method to improve engine optimization processes.

The Miller cycle applied to internal combustion engines (using variable valve timing - VVT) has been widely analyzed [15-17] (both theoretically and in practice) and improvements are documented when compared to the conventional Otto cycle. The advantage of the Miller cycle, when compared to other conventional cycles, is particularly important when engines work under part load, which tends to be the most used working condition.

A further and more significant improvement may be reached if the Miller cycle (with VVT) is associated with a compression ratio adjusting device (variable compression ratio - VCR). It has been proven [16] that the thermal efficiency improvement of this technology association leads to high levels of thermal efficiency, comparable to Diesel engines.

Looking specifically to internal combustion engines for automotive applications, they are mainly used under part load conditions. Under these conditions the thermal efficiency of the engine decreases significantly [16]. It was proven theoretically that the Miller cycle could replace the Otto cycle, when working under part load conditions, with significant improvements in terms of engine thermal efficiency. Further more, the Miller cycle with compression ratio adjustment is much more thermal efficient than the Otto cycle at part load operation. The analysis performed to the Miller cycle [16], using the first law of thermodynamics, prove that cycle 
expansion can be performed until the point where the pressure inside the cylinder equals the environment pressure, achieving the maximum efficiency condition.

\section{MILLER CYCLE}

The Miller cycle is an over-expanded cycle based on the theoretical Otto cycle. The over-expansion is achieved by the reduction of the admission (and compression) stroke, with an associated reduction of the amount of fuel used in the cycle. This reduction may be realized by late intake valve closure (LIVC) as during the intake stroke some of the air and fuel mixture is blown back to the intake manifold, during process 5-1 of figure 1. Also, the reduction of the admission (and compression) stroke can be performed by Early Intake Valve Closure (EIVC) (figure 2). After the valve closure the pressure inside the cylinder reduces below the intake pressure (7-8 of figure 2). During compression, the cylinder pressure raises to the intake pressure near the same piston position where the valve was closed (point 1 of figure 2). Using this cycle with over-expansion, the pressure and temperature of the burnt gases inside the cylinder reduce more rapidly than in a conventional engine. This leads to lower pressure and temperature during the blow-down phenomenon at the exhaust valve opening, meaning that the work potential of those burnt gases was better used during the expansion.

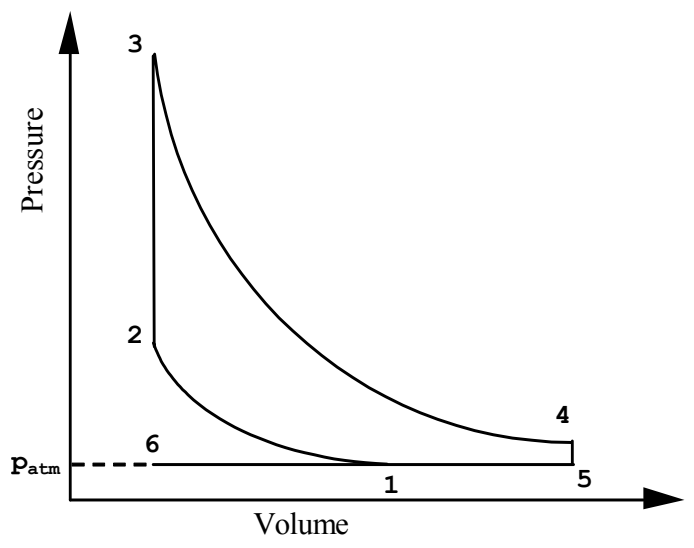

Figure 1 - Miller cycle with LIVC.

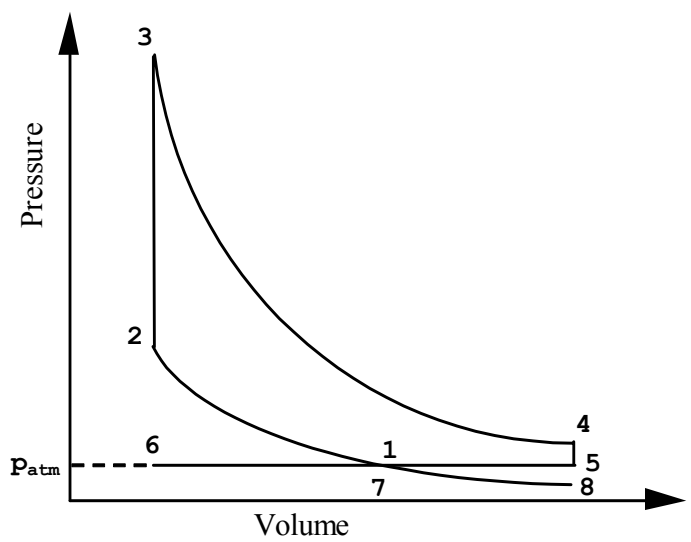

Figure 2 - Miller cycle with EIVC.
With this engine configuration the effective compression ratio (relation between the volume at the intake valve closure and the minimum cylinder volume at TDC) reduces as the valve closes later (in LIVC) or earlier (in EIVC), using a VVT system. If the VVT system is associated to a VCR system, the effective compression ratio should always be adjusted to have the same effective compression ratio, set to pre-knock conditions.

\section{ENTROPY GENERATION MODEL}

A computer model for simulation of internal combustion engines based on the first and second law of thermodynamics and implemented in MATLAB SIMULINK [18] designed at the University of Minho is capable of calculating the entropy generation rate due to the various processes inside the engine. In this model, the system is considered as the volume inside the cylinder of the engine. In the case of the Otto cycle is considered also a throttle valve (for load control) before the intake valve. The processes considered as the principal contributors to the entropy generation in the engine are combustion, free expansion of gas during exhaust, heat transfer, fluid flow through valves, viscous friction of the fluid inside the engine and in some engine configurations (Otto cycle) the throttle valve. A scheme of this model is presented in Figure 3. The first law model is a one zone model capable of calculate instantaneous pressure and temperature of the gases inside the engine, using the First Law of Thermodynamics. Gas characteristics (specific heats and gas constant) inside the engine change with temperature. Combustion is simulated by the use of Wiebe function, allowing the variation of combustion duration and start point.

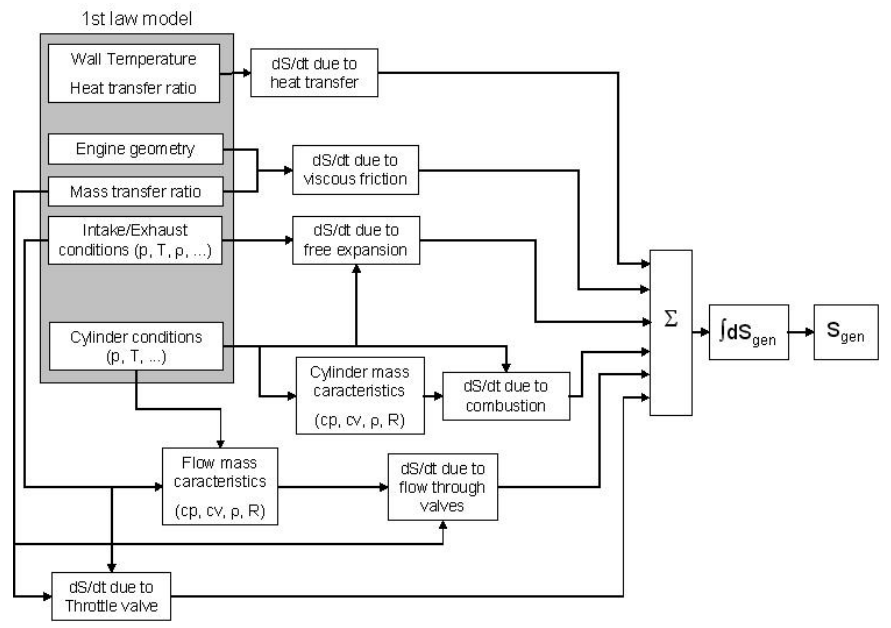

Figure 3 - Computer model structure for entropy generation calculation.

The entropy generated due to the heat transfer is caused by the difference between the temperature of the gas and of the walls: The heat transfer flow rate is calculated based on the Annand heat transfer coefficient and the wall temperatures are considered constant although with different values for the cylinder, piston and engine head. 


$$
\dot{S}_{\text {gen, heat }}=\frac{\dot{Q}_{W}}{T_{W}}-\frac{\dot{Q}_{\text {gas }}}{T_{\text {gas }}}>0
$$

where $Q$ means the heat transferred and $T$ are temperatures, $W$ referring to walls and gas for the gases inside the engine. The heat transfered to the walls has the same value of the heat losted by the gases inside the engine.

The entropy generated due to the free expansion is calculated base on the Gouy-Stodola theorem.

$$
\dot{I}=\dot{W}_{\text {lost }}=T_{0} \dot{S}_{g e n}=\dot{W}_{\text {rev }}-\dot{W}
$$

$\dot{W}$ is 0 as the expansion is considered a free expansion. The reversible work $\left(\dot{W}_{\text {rev }}\right)$ is calculated considering an isentropic expansion at the several valves. When applied to the case of the engine, (2) may be written in terms of mass flowing in and flowing out of the negine as:

$$
\dot{S}_{\text {gen,exp }}=\sum_{\text {in }} \frac{\dot{m}}{T_{0}}\left(h-h_{0}\right)-\sum_{\text {out }} \frac{\dot{m}}{T_{0}}\left(h-h_{0}\right)
$$

where $h$ is the enthalpy of the flowing gases.

The chemical reaction that takes place during combustion, leads to an entropy generation that corresponds to the difference of the entropy of the exhaust gases and the entropy of the reactants. It is written as:

$$
\dot{S}_{g e n, c o m b}=\sum_{i=1}^{p} \dot{n}_{p i} \bar{S}_{p i}-\sum_{i=1}^{r} \dot{n}_{r i} \bar{s}_{r i}=\dot{S}_{3}-\dot{S}_{2}
$$

where 2 and 3 are the points of start and end of combustion, $\dot{n}$ are molar flow rates and $r$ and $p$ are combustion reactants and products, respectively.

The entropy generated due to the flow of gases through the valves (including the throttle valve), is expressed as:

$$
\dot{S}_{\text {gen,valve }}=\dot{m} \int_{c}^{p} d s=\dot{m} c_{p} \ln \left[\left(1-\frac{k-1}{2} M^{2}\right)\left(\frac{p_{u}}{p_{d}}\right)^{\frac{k-1}{k}}\right]
$$

where $M$ is the Mach number, $k$ is the specific heats relation, $p$ is the pressure and $u$ and $d$ represent upstream and downstream in relation to the valve.

Viscous friction within the cylinder is another factor, although negligible.

The model is used hereafter to calculate the entropy generated in an internal combustion engine working under the Miller cycle with compression ratio adjustment, at different working conditions.

\section{ENTROPY GENERATION IN THE MILLER CYCLE}

Using the computer model described above, the Miller cycle with LIVC and VCR was simulated. The valve closure was changed by increasing or decreasing the dwell angle (which corresponds to the period at which the intake valve stays at the maximum lift). The total amount of entropy generated and the importance of each process to the overall entropy generated per cycle are presented at Figure 4 and Figure 5 respectively. Note that an increase of the dwell angle leads to a decrease of trapped mixture inside the cylinder (decrease of the load).

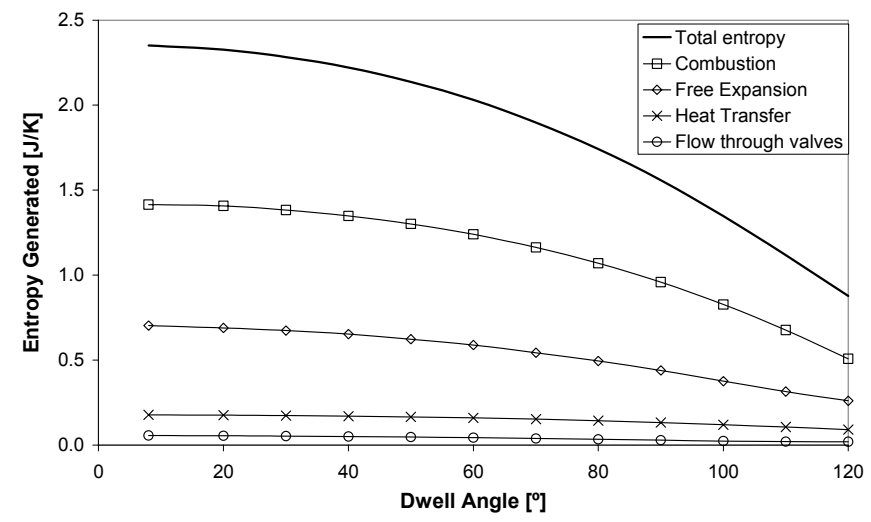

Figure 4 - Total entropy generated in the Miller cycle.

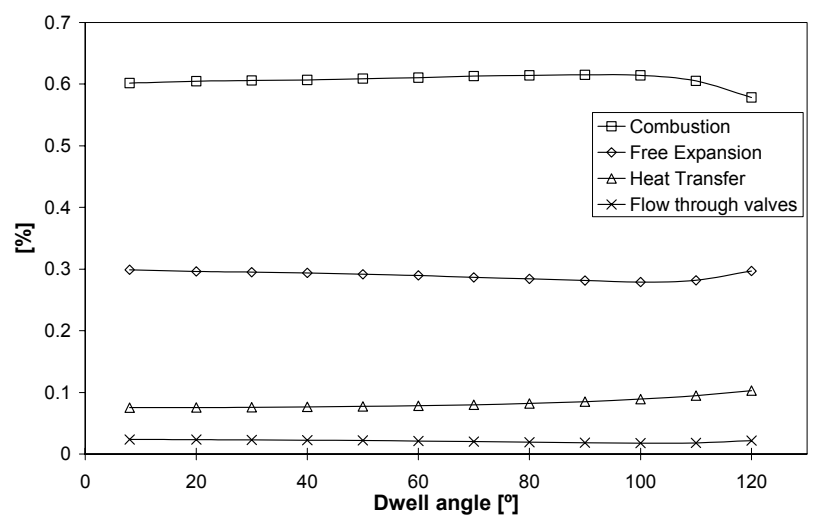

Figure 5 - Importance of each one of the processes in the total entropy generated in the Miller cycle.

From figure 4 it is possible to see that the combustion is the main entropy generating process, followed by the free expansion at the exhaust valve. The heat transfer from the gases to the walls and the flow of gases through the valves during intake and exhaust represent significantly lower components of the total entropy generated in the engine cycle. As the dwell angle increases to values higher than 100 crank angle degrees, an inversion phenomenon can be seen (figure 5). This may be explained by the excessive over-expansion obtained with those values of delay of intake valve closure. Under these working conditions the amount of fuel induced and burnt reduces significantly, reducing the importance of the combustion process in the overall entropy generated. The other processes 
do not decrease as much as combustion, meaning that their importance has a relative increase.

Due to the great importance of the combustion process on the total entropy generation of the engine, it will be studied deeply in relation to some effects.

\section{COMBUSTION}

The combustion process may be changed by altering two variables, the spark timing (start of combustion) and the combustion duration. In real engines, the change of the spark time is possible in every working conditions. Controlling the combustion duration is more complicated because it depends on the fuel used, engine speed and the geometry of the combustion chamber and intake ducts, which generate different turbulence patterns of the gases, allowing a faster or slower progress of the combustion process.

In the following analysis, the combustion duration is considered a constant at 40 crank angle degrees. Firstly analyzing the effect of the spark time in the entropy generation process it is possible to identify two different effects. In the first analysis presented above, the spark timing was set always to $15^{\circ}$ BTDC. To study combustion, the spark timing was changed from $20^{\circ}$ BTDC to $5^{\circ}$ BTDC for the Otto cycle. An increase of the entropy generated was registered with this change (see Figure 6). Due to the fact that the burning process starts later and takes the same time, the maximum pressure and temperature in the cycle are reached later. Furthermore, the temperature and pressure at the exhaust valve opening is higher as the spark time is delayed. This fact leads to an increase of the entropy generated due to the increase of free expansion entropy generated during exhaust.

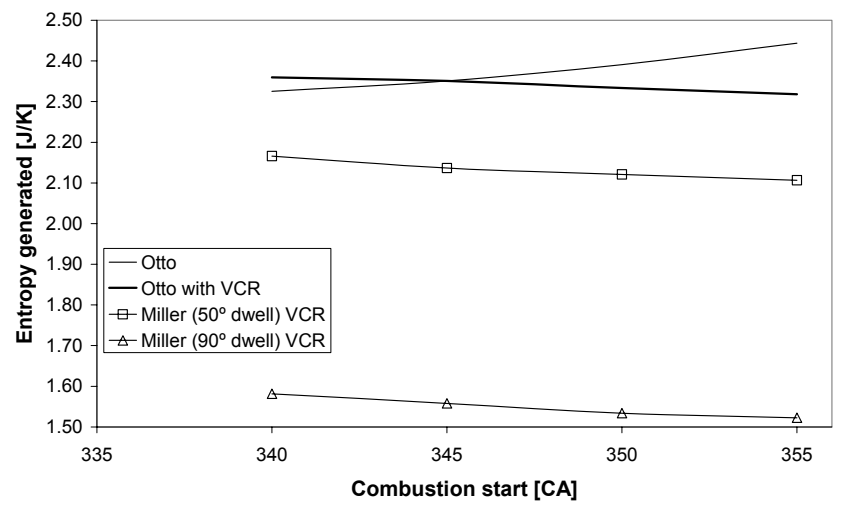

\section{Figure 6 - Entropy generation variation due to spark timing variation.}

The decrease of the entropy generation due to the spark delay is also a benefit in terms of the specific entropy generation (entropy generated / work produced) as can be seen in Figure 7.

As the ignition delay is increased, the maximum pressure and temperature of the cycle also increases, leading to knock onset. To avoid this, the compression ratio is adjusted to the spark time delay in the Otto cycle (figure 6). A reduction of the generated entropy is noticed with this engine configuration.
If the combustion start angle is changed in the Miller cycle with VCR a reduction effect of the entropy generated is achieved. In reality if compression ratio is adjusted for the valve timing variation and for the spark time delay change, an increasing improvement may be reached with this engine configuration. This effect is very clear in Figure 6 and Figure 7.

To reach these working conditions the management of the engine must be controlled by the input signal from a knock sensor. The information given by this sensor will be used to adjust the compression ratio to the optimal conditions just prior to knock onset.

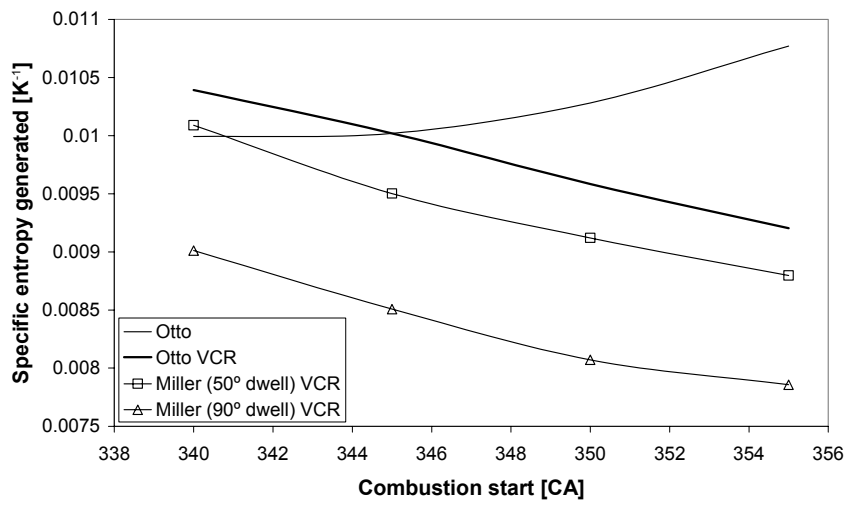

Figure 7 - Specific entropy generated as a function of the combustion start angle.

Recently it was concluded [19] that in a combustion process, the maximum exergy destruction is due to inefficient thermal energy exchange accompanying the oxidation reactions, while the oxidation reaction is relatively efficient, having an exergetic efficiency of about $90 \%$. Due to the importance of the combustion process in the overall entropy generation, the detail of such an analysis shall be used in future work, so that significant improvement of internal combustion engines may be achieved, by changing the combustion parameters.

\section{ENGINE SPEED}

The entropy generation increases in a general way with engine speed. In figure 9 and 10 it is possible to see the evolution of the entropy generated with the speed variation of the engine for an Otto cycle engine and two Miller cycle engines with VCR.

As the speed increases (figure 8), the absolute values of the entropy generated reduce for the global heat transfer and for the free expansion occurring at the intake valve. On the other hand as the speed increases, the entropy generated in the combustion process and in the free expansion process on the exhaust valve increases. This fact is explained because of the reduced time for these processes to happen. In the combustion process a faster burning speed (combustion duration is set always at $40^{\circ}$ of crank angle) may lead to higher temperatures and higher specific heats of the products of the combustion process. Also, as the speed increases, the blow-back phenomenon that happens during intake, reducing the amount of fuel used in the cycle, is not so significant and the entropy generated by the combustion 
process increases due to the increase of the amount of fuel used.

As the pressure at the opening of the exhaust valve is similar at all engine speeds, the velocity of the gases across the exhaust valve also increases with the increase of the engine rpm. Due to higher engine speed (less time) the exhaust will take place in a shorter time, increasing the mass flow rate. This leads to the increase of the entropy generated due to the free expansion and fluid flow through the valve.

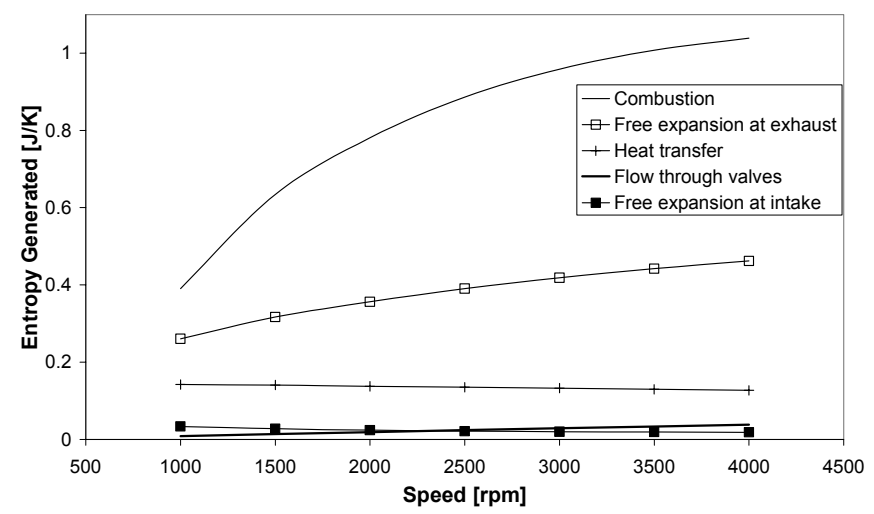

Figure 8 - Entropy generation due to several processes inside the engine.

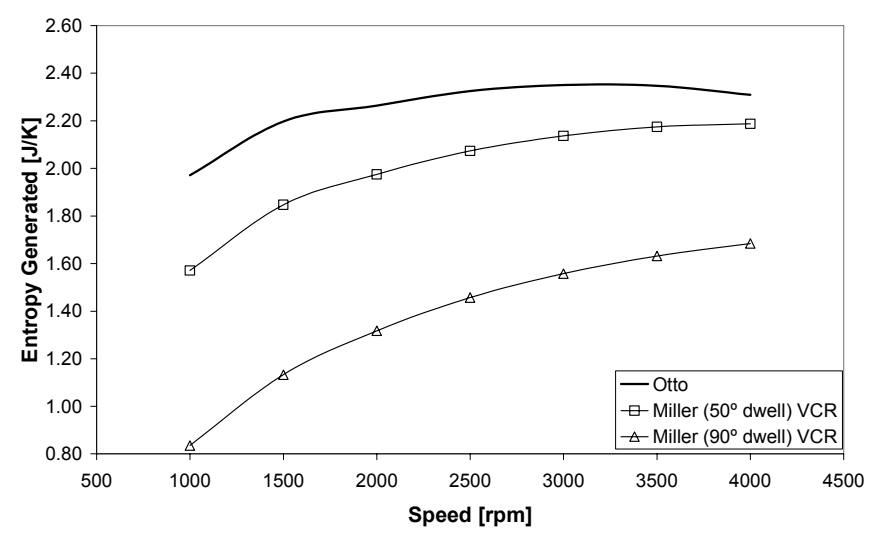

Figure 9 - Entropy generation as a function of speed.

\section{PART LOAD OPERATION}

The Otto cycle working under part load conditions was previously analyzed [16] and proved to perform poorly than the Miller cycle without compression ratio adjustment. When the Otto cycle is compared to the Miller cycle with compression ratio adjustment its advantage is clearer. In figure 11 these three cycles are compared in terms of the total entropy generated and in figure 12 in terms of specific entropy generated. It can be seen (from figure 11) that, as the load reduces down to $60 \%$, the entropy generated is always reducing in the Miller cycle with VCR when compared with the Otto cycle. The same difference is also evident in relation to the Miller cycle without VCR.

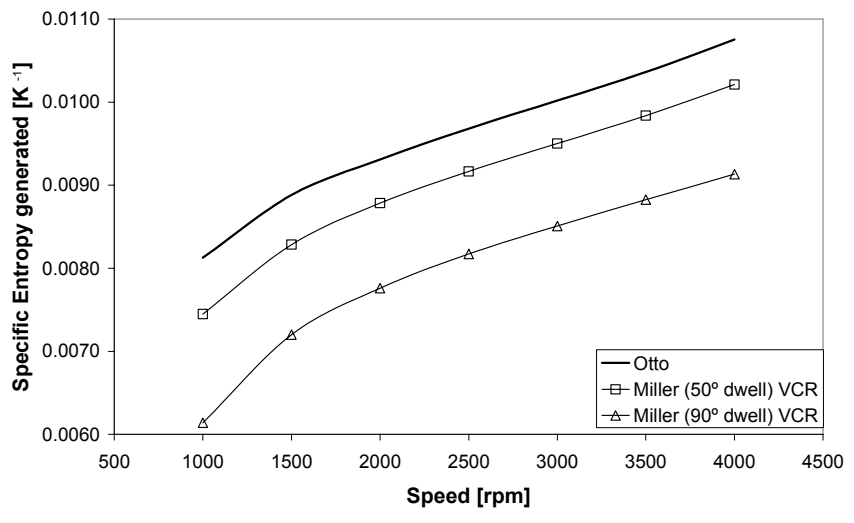

Figure 10 - Specific entropy generated as a function of speed.

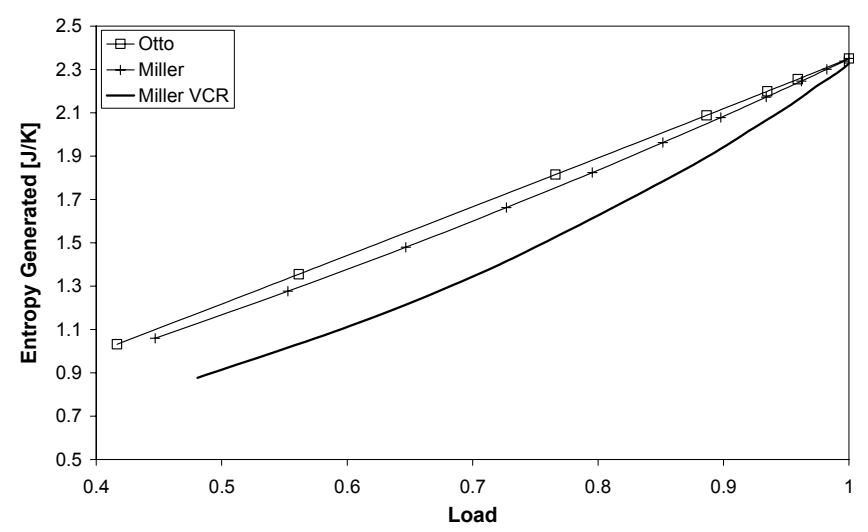

Figure 11 - Entropy generated per cycle for the three engine configurations.

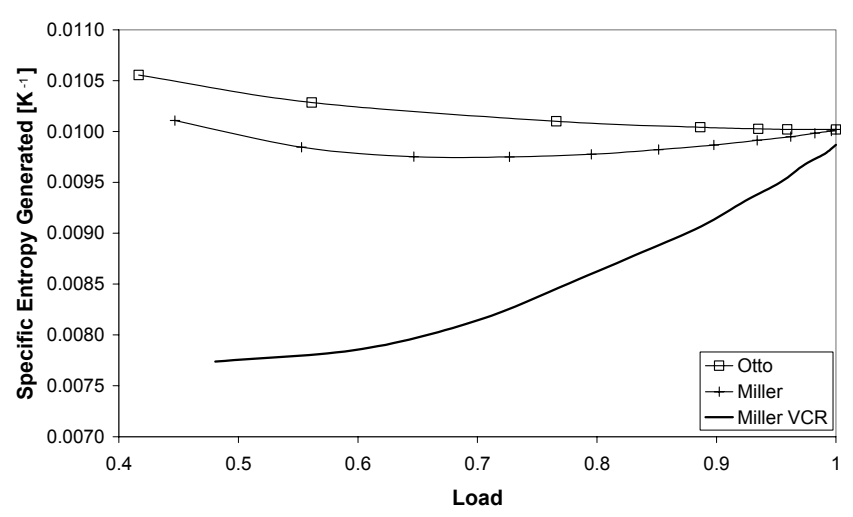

\section{Figure 12 - Specific entropy generated for the three engine configurations.}

When analyzing the specific entropy generated (interpreted as the entropy generated by the useful work produced), the Miller cycle engine with compression ratio adjustment has a significant advantage in relation to the other two analyzed cycles, proving again to be the best working cycle to be implemented in applications for part load operation. 
From these figures it is possible to see that the Miller VCR engine cycle has a better method for load control than the other cycles. In fact, in the Otto cycle, the throttle valve introduces a significant amount of entropy generated. At the same time, the continuous compression ratio adjustement allows the combustion conditions to be kept constant for any load, and as maximum pressure and temperature are constant and at its maximum value (before knock onset), the work produced per cycle is higher, reducing the specific entropy generated as stated in figure 12.

\section{CONCLUSION}

An entropy generation model was used with the Miller cycle engine with compression ratio adjustment. An increase of the engine output is reached in terms of the total entropy generated per cycle. The same tendency is shown in terms of specific entropy generated per cycle.

The combustion process and the free expansion during exhaust are the processes where significant gains in terms of entropy reduction are possible. The heat transfer and the flow through the valves represent a small fraction of the overall entropy generated and improvements in these entropy generating processes do not bring significant reduction to the total generated entropy.

From the analyzed engine cycles, the most interesting engine (in terms of minimum entropy generation) is the Miller cycle with VCR, working with a dwell angle near $100^{\circ}$ of crank angle and at the slowest possible speed.

When working under part load, the Miller cycle engine with compression ratio adjustment is the best working solution (among the analyzed engines).

\section{NOMENCLATURE}

EGM - Entropy Generation Minimization

VCR - Variable Compression Ratio

VVT - Variable Valve Timing

TDC - Top Dead Centre

\section{ACKNOWLEDGMENTS}

Bernardo Ribeiro thanks the FCT and FSE (in the scope of QCA III) for the financial support given for his research activities.

\section{REFERENCES}

[1] Curzon, F. L., Ahlborn, B. Efficiency of a Carnot Engine at Maximum Power Output, Am. J. Phys. 43, 22 (1975).

[2] Kodal, A., Sahin, B., Yilmaz, T., A Comparative Performance Analysis of Irreversible Carnot Heat Engines Under Maximum Power Density and Maximum Power Conditions, Energy Convers. Mgmt., 2000, 41, 235.
[3] Parlak, Adnan, Comparative Performance Analysis of Irreversible Dual and Diesel Cycles Under Maximum Power Conditions, Energy Convers. Mgmt., 2005, 46, 351.

[4] Chen, Lingen et. al. Efficiency of an Atkinson Engine at Maximum Power Density, Energy Convers. Mgmt., 1998, 39 (3/4), 337.

[5] Arias-Hernández, L. A., Angulo-Brown, F. A General Property of Endoreversible Thermal Engines, J. Appl. Phys. 81 (1997) 2973.

[6] Angulo-Brown, F., Arias-Hernández, L. A., PáezHernández, R., A General Property of non-endoreversible Thermal Cycles, J. Phys. D: Appl. Phys. 32 (1999) 1415-1420.

[7] Bejan, A., Entropy Generation Through Heat and Fluid Flow, John Wiley\& Sons, New York, 1994.

[8] Bejan, A., Fundamentals of Exergy Analysis, Entropy Generation Minimization, and the Generation of Flow Architecture, Int. J. Energy Res. 2002; 26:545-565.

[9] Bejan, A., Advanced Engineering Thermodynamics, Second Edition, John Wiley \& Sons, New York, 1997.

[10] Bejan, A., Entropy Generation Minimization, CRC Press, Boca Raton, 1996.

[11] Caton, J., A review of investigations using the second law of thermodynamics to study internal-combustion engines, SAE 2000-01-1081, 2000.

[12] Caton, J., Operating characteristics of a sparkignition engines using the second law of thermodynamics: Effects of speed and load, SAE 2000-01-0952, 2000.

[13] Caton, J., On the destruction of availability (exergy) due to combustion processes-with specific application to internal-combustion engines, Energy, Vol. 25, Issue 11, November 2000, 1097-1117

[14] Caton, J., A cycle simulation including the second law of thermodynamics for a spark ignition engine: Implications of the use of multiple-zones for combustion, SAE 2002-01-0007, 2002.

[15] Flierl, R, Kluting, M., The Third Generation of Valvetrains-New Fully Variable Valvetrains for Throttle-Free Load Control, SAE 2000-01-1227, 2000.

[16] Martins, J., et. al. Thermodynamic Analysis of an Over-Expanded Engine, SAE 2004-01-0617, 2004.

[17] Martins, J., Ribeiro, B., Fuel Consumption Reduction By Adopting A Different Spark Ignition Engine Cycle, IEA int. meeting - Advances in Technology and Instrumentation to Guarantee the Reduction of GHG in Different Sectors, Lisbon, 2004.

[18] Ribeiro, B, Martins, J., Thermodynamic Analysis of SI Engines Using EGM, paper under submission.

[19] Lior, N., Irreversibility in Combustion, presented at the First international Conference on Applied Thermodynamics, ECOS'01, July 4-6, 2001, Istanbul 